\title{
Effects of physical therapy in older women with urinary incontinence: a systematic review
}

\author{
Efeitos do tratamento fisioterapêutico em mulheres idosas com incontinência \\ urinária: uma revisão sistemática
}

Vanessa S. Pereira, Adriana C. Escobar, Patricia Driusso

\begin{abstract}
Background: Urinary incontinence (UI) is one of the most common public health problems among older women. Despite conservative treatment being recommended as the first treatment option, the effects of physical therapy in older women with UI is unclear. Objective: This study aimed to systematically review the evidence about the effects of physical therapy on urinary symptoms in older women with UI. Method: The literature search for studies evaluating conservative treatment for incontinent in elderly women was conducted on Pubmed/Medline, Lilacs, Scielo, ISI Web of Knowledge and PEDro. We selected clinical trials published in English and Portuguese after the year 2000. The methodological quality of the studies was assessed using the PEDro scale. The results were analyzed using a critical review method. Results: Six studies were reviewed in full revealing that pelvic floor muscle training was the treatment option in most studies. Five of the six selected studies were classified as having high methodological quality. There was significant improvement in urinary symptoms after treatment in five of the six selected studies. Conclusions: It was concluded that physical therapy treatment seems to be effective to decrease urinary incontinence symptoms in older women. However, the small number of studies and the use of concurrent interventions limit the conclusions on this issue.
\end{abstract}

Keywords: urinary incontinence; rehabilitation; treatment outcome; elderly health.

\section{Resumo}

Contextualização: A incontinência urinária (IU) é um dos mais comuns problemas de saúde pública entre as mulheres idosas. Apesar de o tratamento conservador ser recomendado como a primeira opção de tratamento, os efeitos do tratamento fisioterapêutico em mulheres idosas com IU não está esclarecido. Objetivo: Sistematizar as evidências científicas sobre os efeitos do tratamento fisioterapêutico sobre os sintomas miccionais de mulheres idosas com IU. Método: A busca de publicações sobre os efeitos de modalidades de tratamento fisioterapêutico em mulheres idosas com IU foi realizada nas bases de dados ISI Web of Knowlegde, Medline/Pubmed, Lilacs, Scielo e PEDro. Foram selecionados ensaios clínicos publicados nas línguas inglesa e portuguesa após o ano de 2000. A qualidade metodológica dos estudos foi avaliada pela Escala PEDro, e a análise dos resultados dos estudos foi realizada por meio de revisão crítica dos conteúdos. Resultados: Seis estudos foram revisados na íntegra, revelando-se que os exercícios de fortalecimento da musculatura do assoalho pélvico foram o tratamento de escolha na maioria dos estudos. Cinco dos seis estudos selecionados foram classificados como de alta qualidade metodológica. Houve melhora significativa dos sintomas miccionais após o tratamento proposto em cinco dos seis estudos selecionados. Conclusões: Conclui-se que o tratamento fisioterapêutico parece ser efetivo para a redução dos sintomas miccionais em mulheres idosas com IU. No entanto, o pequeno número de estudos e a aplicação de técnicas em conjunto limita as conclusões sobre o tema.

Palavras-chave: incontinência urinária; reabilitação; resultado de tratamento; saúde do idoso.

Received: 11/10/2011 - Revised: 05/03/2012 - Accepted: 06/12/2012 


\section{Introduction $: \because 8$}

According to the International Continence Society (ICS), urinary incontinence (UI) is defined as any involuntary leakage of urine ${ }^{1}$. It is one of the most common health problems among women of all ages, with an increase in prevalence with aging ${ }^{2}$. It is estimated that $25 \%$ to $45 \%$ of women, of different ages and throughout the world, suffer from involuntary urine leakage, while $9 \%$ to $39 \%$ of women over 60 years of age report daily urinary leakage ${ }^{3}$. In Brazil, studies indicate that between $26.2 \%$ and $35 \%$ of post-menopausal women suffer from UI ${ }^{4.5}$. Furthermore, the leakage of urine results in severe consequences for the quality of life of the women affected, producing social, emotional and psychological impacts ${ }^{6}$.

In light of the high prevalence and the economic, social and psychological consequences of UI in older women, it is necessary to determine an effective treatment for this disorder. The ICS recommends conservative treatment as the first line of treatment for incontinent women with a focus on increasing strength and correcting activating patters of the pelvic floor muscles? ${ }^{7}$. Pelvic floor muscles training without the use of any device, as proposed by Kegel ${ }^{8}$ in 1948, was the first technique used for the strengthening and improvement of pelvic floor muscle recruitment. Currently, several techniques are employed in clinical practice aiming to improve pelvic floor muscle function, and among the most commonly used are electrical stimulation, biofeedback and vaginal cones .

Since older women may present pelvic floor age related changes, the effects of physical therapy on older women with UI are not clear. Authors suggest that, in older women, there may be a reduction in the integrity of the pelvic floor due to changes caused by a reduction in the dosage of female reproductive hormones and aging, such as changes in the rate of different types of collagen and the preferential atrophy of type II muscle fibers ${ }^{10-12}$. The presence of these changes raise doubts in regards to the real effectiveness of conservative treatment for older women with UI. Therefore, this study aimed at systematically reviewing the scientific evidence on the effects of physical therapy on urinary incontinence symptoms in older women.

\section{Method $: \because$.}

We systematically reviewed clinical trials that addressed the different forms of physical therapy available for the treatment of UI in older women. The literature search was performed on April 20, 2012 on the ISI Web of Knowledge, Medline/Pubmed, Lilacs, Scielo and PEDro databases. The keywords urinary incontinence and older women, combined with rehabilitation or physical therapy, were used as search strategies. Two blinded researchers conducted the search independently and compared the results.

Randomized clinical trials that were published in English and Portuguese were considered for inclusion in this review. The study content was analyzed by two evaluators and selected using the following inclusion criteria: a) participants with reported complaint of urinary leakage; b) sample composed of older women only (aged over 60 years); c) investigation of the effects of some physical therapy technique; d) studies published after the year 2000. Studies that dealt with surgical interventions were excluded.

Articles were analyzed in full using a structured form with the following items: sample, outcomes evaluated, intervention characteristics and treatment effects ${ }^{13}$. Methodological quality of the selected clinical trials was assessed using the ${ }^{14}$ PEDro Scale that consists of eleven questions, ten of which are summed to a final score. Each criterion is scored according to its presence or absence. Items not described in the studies are classified as "not listed" and are not scored. The final score ranges from 0 to 10 and are obtained through the sum of all positive responses. All selected studies were indexed in the PEDro database and therefore, quality scores were extracted from the database. Studies with scores equal to or greater than five were considered of high methodological quality ${ }^{15}$.

\section{Results $: \because$.}

Forty nine articles were found using the described search strategy. We excluded repeated studies, literature reviews and those that did not fulfill the proposed inclusion criteria. Twelve studies were selected for full text screening. Among those selected, four evaluated only one intervention arm ${ }^{16-19}$ and two had a sample of women starting from 55 years of age $\mathrm{e}^{20,21}$ and were therefore excluded (Figure 1). Thus, six studies were included in the critical appraisal stage. Table 1 shows the main characteristics of the included studies.

A content analysis of the selected studies revealed the heterogeneity of the treatment modalities evaluated in the studies. In five of the studies, pelvic floor muscle training exercises were the treatment of choice in at least one of the treated groups ${ }^{22-26}$. However, this treatment was employed in isolation in only two 
studies $^{22,26}$. In two of the selected studies, the authors applied non-invasive transcutaneous electrical stimulation on the tibial nerve ${ }^{25}$ and extracorporeal magnetic stimulation ${ }^{27}$. In another study, an intervention of intravaginal electrical stimulation was applied in isolation ${ }^{22}$.

Three studies included women with reported complaints of leakage related to stress or urge ${ }^{22,24,27}$. Kim et al..$^{23}$ and Sherburn et al. ${ }^{26}$ evaluated treatment effects in women with stress UI only, while Schreiner et al. ${ }^{25}$ dealt with women with urge UI alone. The sample size of the included studies ranged from $37^{22}$ to $101^{27}$. The average age varied from $67.6^{25}$ to $79.4^{24}$ years. The age inclusion criteria was different between the included studies. Schreiner et al. ${ }^{25}$ and Wallis et al. ${ }^{27}$ considered 60 as the minimum age for the sample. On the other hand, Spruijt et al. ${ }^{22}$, Kim et al. ${ }^{23}$, Aslan et al. ${ }^{24}$ and Sherburn et al. ${ }^{26}$ considered 65 as the minimum age. In all of the studies, the sample was composed of community based women while Aslan et al. ${ }^{24}$ evaluated women in long term institutional care.

Outcome measures to evaluate incontinence symptoms included: the micturition diary ${ }^{2427}$, different forms of pad tests $s^{22,24,26,27}$ and the frequency of episodes of urinary leakage ${ }^{23}$. Other outcomes evaluated were quality of life using the King's Health Questionnaire (KHQ) ${ }^{24,25}$, the International Consultation on Incontinence Questionnaire - Short Form (ICQ-SF) ${ }^{26,27}$ and the indirect strength of the pelvic floor muscles ${ }^{22,24}$. A significant improvement in incontinence symptoms after the proposed treatment was noted in five of the six studies selected ${ }^{22-26}$. A long term follow up between 6 months $^{24}$ and 1 year ${ }^{23}$ were collected in three studies ${ }^{23,24,26}$. The results demonstrated that the effects were maintained over the long term.

Table 1 also shows the PEDRo scale methodological quality scores. It can be observed that, among the six studies selected, five had a score greater than or equal to five and therefore were considered as having high methodological quality.

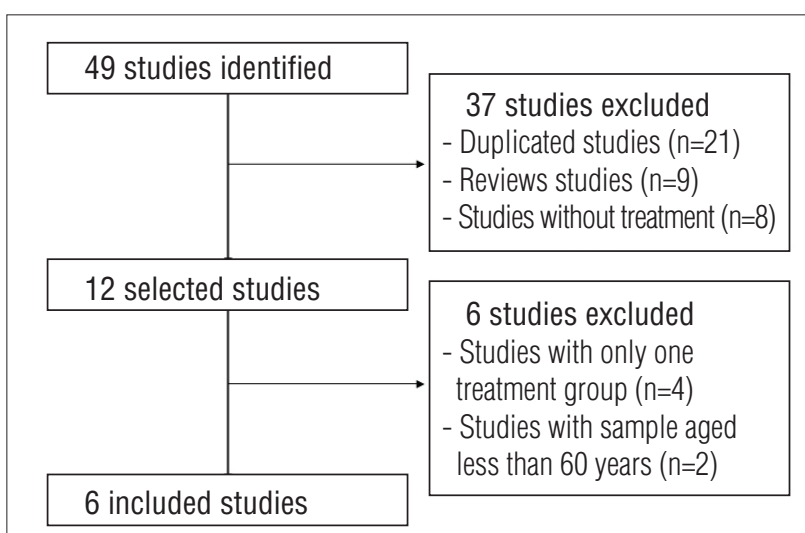

Figure 1. Flow chart of the search and selection of articles during the systematic review process.

\section{Discussion $: \because$.}

The results of this review demonstrated that regardless of the UI type and the treatment modality applied, physical therapy interventions appear to promote benefits in incontinent older women, as an improvement in urinary symptoms was observed in all studies except one. It is known that urinary incontinence is one of the most important and most common geriatric problems ${ }^{16}$. The high prevalence of urinary incontinence among older women may possibly be explained by the sum of the effects of post-menopausal hypoestrogenism and aging, which produce deleterious effects in the female urogenital tract ${ }^{10}$. The results of this review show that, despite the presence of structural age related changes, physical therapy can promote an improvement of incontinence symptoms in older women.

Pelvic floor muscle training was the modality of choice for the majority of the studies selected. Numerous studies have evaluated the effectiveness of this type of treatment when compared to the absence of treatment for women with UI. In a recent review, Dumoulin and Hay-Smith ${ }^{28}$ evaluated the effects of pelvic floor muscle training in women with stress UI compared to those who remained untreated. Analysis of the eight studies selected showed that incontinent women submitted to treatment had 17 times more chance of improving or curing urinary symptoms than untreated women. Therefore, the strengthening of the pelvic floor muscles seems to be effective in the treatment of urinary incontinence in women.

However, for older women, this therapy is still little explored. Of the studies that addressed treatment in older women, none investigated the effects of pelvic floor muscle training applied in isolation as compared to an inactive control group. Only Kim et al..$^{23}$ and Aslan et al..$^{24}$ compared a group treated with pelvic floor muscle training in conjunction with multidimensional exercises and bladder training to an inactive control group. This lack of studies evaluating pelvic floor exercises in isolation makes it difficult to reach any conclusions about this type of treatment, particularly in the aged population.

Schreiner et al..$^{25}$ addressed a recently proposed technique for UI treatment. The authors evaluated the effects of traditional therapy in conjunction with transcutaneous electrical stimulation of the posterior tibial nerve in the treatment of older women with urge UI, achieving superior results to traditional therapy in isolation. Amarenco et al. ${ }^{29}$ evaluated the acute effects of this technique on urodynamic parameters and found a reduction in hyperactivity and an increase in bladder capacity after application. The physiological effects of this treatment may be explained by the presence of posterior tibial nerve afferent fibers in the same sacral projection of the bladder innervation. In this way, the stimulation of this nerve's 


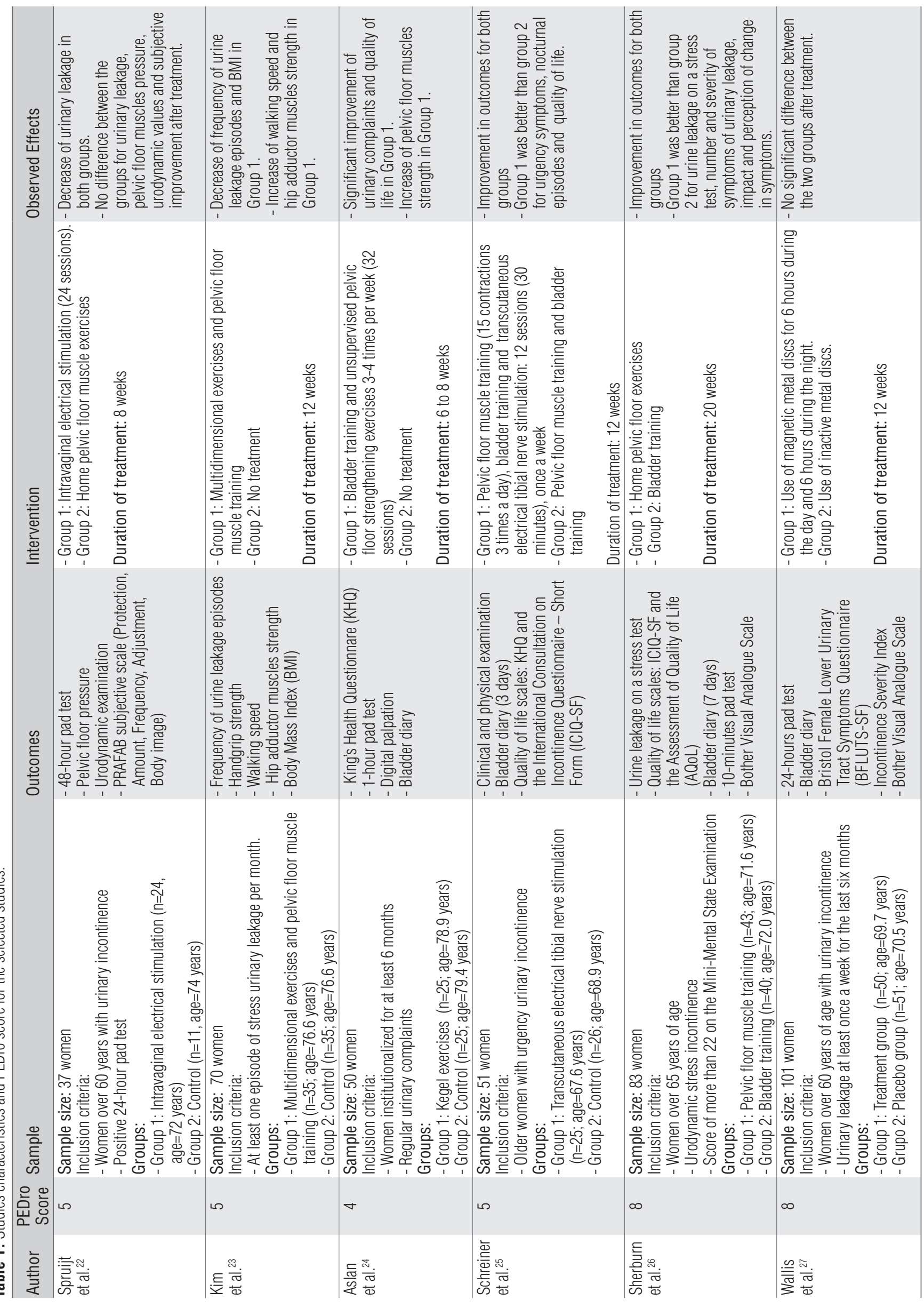


afferent fibers would produce a neuromodulation in the region, inhibiting detrusor muscle afferent fibers, thereby reducing the urge sensation ${ }^{29}$. Vandoninck et al. ${ }^{30}$ treated women with UI symptoms for 12 weeks using electrical stimulation of the posterior tibial nerve and found that $70 \%$ of the women reported a reduction in urinary leakage episodes. The results with respect to this technique are encouraging, although the presence of just one study with the application of this therapy in the elderly population does limit conclusions.

Another form of non-invasive treatment is extracorporeal magnetic stimulation, based on the principle that a change in the magnetic field can induce an electron flow, which would allow for the depolarization and contraction of the pelvic floor muscles ${ }^{31}$. This technique would also be well received by older women as it is performed without the need to undress and without pain or discomfort. Wallis et al. ${ }^{27}$ tested the effectiveness of this technique in this population and did not find any positive results when compared to the group that received placebo treatment, demonstrating a strong influence of the placebo effect on the results. However, the sample size of the included study limits conclusions on this technique and further studies must be performed.

The long term follow up of physical therapy results is essential in reaching conclusions on the effectiveness of the interventions. All of the selected studies that included a long term follow-up evaluated pelvic floor muscle training. It is known that it is necessary to continue the exercises in order to maintain the benefits of pelvic floor muscle training $^{32}$. It is also known that adherence to post treatment exercises can be influenced by barriers, such as the lack of information and discipline, reduction of the time and willingness in its execution, the presence of stressful situations and the difficulty in integrating the exercises into daily life activities $^{33}$. As such, it is essential to make clear to the patients the importance of continuing the exercises post intervention in order to maintain the results after the physical therapy has ended.

In this review, it was noted that just one study evaluated the effects of physical therapy for UI in institutionalized older women. UI is highly prevalent in institutionalized older women, being considered one of the principal causes of institutionalization. The existence of co-existing diseases, functional incapacity and fragility, influence the control of the sphincter control and the mobility to a toilette, which may justify the high prevalence of the disorder in this population ${ }^{34,35}$. The literature on the topic demonstrate the psycho-social consequences, such as depression and isolation, and the physiological consequences, such as pressure ulcers, that can occur as a result of this geriatric syndrome in community dwelling women, but little is known of the consequences of this condition in institutionalized older women ${ }^{36}$. In spite of the difficulties, the positive effects of the treatment of institutionalized older women found by Aslan et al. ${ }^{24}$ encourage the insertion of this type of UI treatment in long term care institutions.

The majority of the studies selected had high methodological quality, which facilitates the extrapolation of results for clinical practice. Nevertheless, it should be taken into consideration that three studies had the minimum cut-off score. This systematic review sought to gather current and scientifically sound evidence to enrich clinical practice and assist professionals in determining their clinical practice. However, the small number of clinical trials specifically performed on older women highlights the need for new studies to evaluate the effects of different UI treatment modalities for older women. To reach definitive conclusions these studies must present an appropriate sample size, the application of isolated techniques as a form of determining the real effectiveness of each technique, a the long term follow up in addition to a strong methodological quality.

\section{Conclusion $: \because$.}

Pelvic floor muscle training in isolation or in conjunction with multidimensional exercises, bladder training and non-invasive transcutaneous electrical posterior tibial nerve stimulation seem to be effective techniques in the reduction of urinary symptoms among older women with UI. However, the small number of studies and the use of concurrent treatment techniques limits conclusions about the efficacy of specific interventions and therefore, new studies need to be conducted to provide a more definitive conclusion on the effects of physical therapy in the treatment of UI in older women.

\section{Acknowledgements $: \because$.}

Fundação de Amparo à Pesquisa do Estado de São Paulo (FAPESP - Research Support Foundation of the State of São Paulo), São Paulo, SP, Brazil for the financial support awarded. 
1. Abrams P, Andersson KE, Birder L, Brubaker L, Cardozo L, Chapple C, et al. Fourth International Consultation on Incontinence Recommendations of the International Scientific Committee: evaluation and treatment of urinary incontinence, pelvic organ prolapsed, and fecal incontinence. Neurourol Urodyn. 2010;29(1):213-40.

2. Temml C, Haidinger G, Schmidbauer J, Schatzl G, Madersbacher S. Urinary incontinence in both sexes: prevalence rates and impact on quality of life and sexual life. Neurourol Urodyn. 2000;19(3):259-71

3. Buckley BS, Lapitan MCM; Epidemiology Committee of the Fourth International Consultation on Incontinence, Paris, 2008. Prevalence of urinary incontinence in men, women, and children - current evidence: findings of the Fourth International Consultation on Incontinence. Urology. 2010;76(2):265-70.

4. Tamanini JTN, Lebrão ML, Duarte YAO, Santos JLF, Laurenti R. Analysis of the prevalence of and factors associated with urinary incontinence among elderly people in the Municipality of São Paulo, Brazil: SABE Study (Health, Wellbeing and Aging). Cad Saúde Pública. 2009;25(8):1756-62.

5. Guarisi T, Pinto Neto AM, Osis MJ, Pedro A0, Paiva LHC, Faúndes A. Incontinência urinária entre mulheres climatéricas brasileiras: inquérito domiciliar. Rev Saúde Pública. 2001;35(5):428-35

6. Dedicação AC, Haddad M, Saldanha MES, Driusso P. Comparison of quality of life for different types of female urinary incontinence. Rev Bras Fisioter. 2009;13(2):116-22.

7. Hay-Smith J, Bø K, Berghmans LC, Hendriks HJ, de Bie RS, van Waalwijk van Doorn ES. WITHDRAWN: Pelvic floor muscle training for urinary incontinence in women. Cochrane Database Syst Rev. 2007;(1):CD001407

8. Kegel AH. Progressive resistance exercise in the functional restoration of the perineal muscles. Am J Obstet Gynecol. 1948;56(2):238-48.

9. Neumann PB, Grimmer KA, Deenadayalan Y. Pelvic floor muscle training and adjunctive therapies for the treatment of stress urinary incontinence in women: a systematic review. BMC Womens Health. 2006;6:11.

10. Chen Y, Chen GD, Hu SW, Lin TL, Lin LY. Is the occurrence of storage and voiding dysfunction affected by menopausal transition or associated with the normal aging process? Menopause. 2003:10(3):203-8

11. Gopal M, Sammel MD, Arya LA, Freeman EW, Lin H, Gracia C. Association of change in estradiol to lower urinary tract symptoms during the menopausal transition. Obstet Gynecol. 2008;112(5):1045-52

12. Rizk DE, Fahim MA. Ageing of the female pelvic floor: towards treatment 'a la carte' of the 'geripause'. Int Urogynecol J Pelvic Floor Dysfunct. 2008;19(4):455-8.

13. Ricci NA, Dias CNK, Driusso P. The use of electrothermal and phototherapeutic methods for the treatment of fibromyalgia syndrome: a systematic review. Rev Bras Fisioter. 2010;14(1):1-9

14. Maher CG, Sherrington C, Herbert RD, Moseley AM, Elkins M. Reliability of the PEDro scale for rating quality of randomized controlled trials. Phys Ther. 2003;83(8):713-21.

15. Moseley AM, Herbert RD, Sherrington C, Maher CG. Evidence for physiotherapy practice: a survey of the Physiotherapy Evidence Database (PEDro). Aust J Physiother. 2002;48(1):43-9.

16. Padrós J, Peris T, Salvà A, Denkinger MD, Coll-Planas L. Evaluation of a urinary incontinence unit for community-dwelling older adults in Barcelona: implementation and improvement of the perceived impact on daily life, frequency and severity of urinary incontinence. Z Gerontol Geriatr. 2008;41(4):291-7.

17. Bakar Y, Cinar Özdemir O, Özengin N, Duran B. The use of extracorporeal magnetic innervation for the treatment of stress urinary incontinence in older women: a pilot study. Arch Gynecol Obstet. 2011;284(5):1163-8

18. Simard C, Tu LM. Long-term efficacy of pelvic floor muscle rehabilitation for older women with urinary incontinence. J Obstet Gynaecol Can. 2010;32(12):1163-6.
19. Sousa JG, Ferreira VR, Oliveira RJ, Cestari CE. Avaliação da força muscular do assoalho pélvico em idosas com incontinência urinária. Fisioter Mov. 2011;24(1):39-46.

20. Burgio KL, Goode PS, Locher JL, Umlauf MG, Roth DL, Richter HE, et al. Behavioral training with and without biofeedback in the treatment of urge incontinence in older women: a randomized controlled trial. JAMA. 2002;288(18):2293-9

21. Johnson TM 2nd, Burgio KL, Redden DT, Wright KC, Goode PS. Effects of behavioral and drug therapy on nocturia in older incontinent women. J Am Geriatr Soc. 2005;53(5):846-50.

22. Spruijt J, Vierhout M, Verstraeten R, Janssens J, Burger C. Vaginal electrical stimulation of the pelvic floor: a randomized feasibility study in urinary incontinent elderly women. Acta Obste Gynecol Scand. 2003;82(11):1043-8

23. Kim H, Suzuki T, Yoshida Y, Yoshida H. Effectiveness of multidimensional exercises for the treatment of stress urinary incontinence in elderly community-dwelling Japanese women: a randomized, controlled, crossover trial. J Am Geriatr Soc. 2007;55(12):1932-9.

24. Aslan E, Komurcu N, Beji NK, Yalcin 0. Bladder training and Kegel exercises for women with urinary complaints living in a rest home. Gerontology. 2008;54(4):224-31.

25. Schreiner L, dos Santos TG, Knorst MR, da Silva Filho IG. Randomized trial of transcutaneous tibial nerve stimulation to treat urge urinary incontinence in older women. Int Urogynecol J. 2010;21(9):1065-70.

26. Sherburn M, Bird M, Carey M, Bø K, Galea MP. Incontinence improves in older women after intensive pelvic floor muscle training: an assessor-blinded randomized controlled trial Neurourol Urodyn. 2011;30(3):317-24

27. Wallis MC, Davies EA, Tahlib L, Griffiths S. Pelvic static magnetic stimulation to control urinary incontinence in older women: a randomized controlled trial. Clin Med Res. 2012;10(1):7-14.

28. Dumoulin C, Hay-Smith J. Pelvic floor muscle training versus no treatment, or inactive control treatments, for urinary incontinence in women. Cochrane Database Syst ver 2010;(10):CD005654

29. Amarenco G, Ismael SS, Even-Schneider A, Raibaut P, Demaille-Wlodyka S, Parratte B, et al. Urodynamic effect of acute transcutaneous posterior tibial nerve stimulation in overactive bladder. J Urol. 2003;169(6):2210-5.

30. Vandoninck V, van Balken MR, Finazzi Agró E, Petta F, Caltagirone C, Heesakkers JPFA, et al. Posterior tibial nerve stimulation in the treatment of urge incontinence. Neurourol Urodyn. 2003:22(1):17-23

31. Olney RK, So YT, Goodin DS, Aminoff MJ. A comparison of magnetic and electrical stimulation of peripheral nerves. Muscle Nerve. 1990:13(10):957-63.

32. Bø K, Kvarstein B, Nygaard I. Lower urinary tract symptoms and pelvic floor muscle exercise adherence after 15 years. Obstet Gynecol. 2005;105(5 Pt 1):999-1005

33. Alewijnse D, Mesters I, Metsemakers J, van den Borne B. Predictors of long-term adherence to pelvic floor muscle exercise therapy among women with urinary incontinence. Health Educ Res. 2003;18(5):511-24.

34. Offermans M, Du Moulin MF, Hamers JP, Dassen T, Halfens RJ. Prevalence of urinary incontinence and associated risk factors in nursing home residents: a systematic review. Neurourol Urodyn 2009:28(4):288-94

35. Coll-Planas L, Denkinger MD, Nikolaus T. Relationship of urinary incontinence and latelife disability: implications for clinical work and research in geriatrics. Z Gerontol Geriatr. 2008;41(4):283-90

36. Durrant J, Snape J. Urinary incontinence in nursing homes for older people. Age Ageing 2003:32(1):12-8. 